http://jmscr.igmpublication.org/home/ ISSN (e)-2347-176x ISSN (p) 2455-0450

crossref DOI: https://dx.doi.org/10.18535/jmscr/v7i8.25

\title{
A comparative study on cardiovascular parameters in Normal \& Type 2 Diabetes mellitus patients
}

\author{
Authors \\ Dr B S Gupta ${ }^{1 *}$, Dr Yogesh Singh ${ }^{2}$ \\ ${ }^{1}$ Professor, Head of Department Physiology, Birat Medical College, Nepal \\ ${ }^{2}$ Assistant Professor, JNU-IMSRC, Jaipur \\ *Correspondence Author \\ Dr B S Gupta \\ Professor, Head of Department Physiology, Birat Medical College, Nepal
}

\begin{abstract}
Background: Diabetes mellitus (DM) is a major public health problem world-wide. It is a significant health care challenge of the 21 st century.

Methods: The study was carried out in 100 Type-2 diabetic patients in the age group of 35-75 years with duration of diabetes ranging from 6 months to 20 years. Control Group consists of 100 normal individuals who matched with case in age, sex and socio economic condition as far as possible.

Results: The mean value of heart rate in 100 Diabetic patients was found to be 84.06 with standard deviation of 11.03 which higher when compared with the mean value of heart rate in 100 normal people which is 82.64 with standard deviation of 10.23. Mean arterial pressure of Diabetic patients was found to be $96.84 \mathrm{mmHg}$ with a standard deviation of 7.84 which again is more than mean arterial pressure of normal persons which is $93.98 \mathrm{mmHg}$ with standard deviation of 7.09.

Conclusion: There is increased need for regular health checkups especially of the cardiovascular system to prevent complications.

Keywords: Diabetes mellitus, Cardiovascular changes, Heart rate, Mean arterial pressure.
\end{abstract}

\section{Introduction}

Diabetes mellitus is a metabolic disorder characterized by the presence of hyperglycemia due to defective insulin secretion, defective insulin action or both. The chronic hyperglycemia of diabetes is associated with relatively specific long-term microvascular complications affecting the eyes, kidneys and nerves, as well as an increased risk for cardiovascular disease (CVD). The diagnostic criteria for diabetes are based on thresholds of glycemia that are associated with microvascular disease, especially retinopathy ${ }^{1}$.
People living with type $2 \mathrm{DM}$ are more vulnerable to various forms of both short- and long-term complications, which often lead to their premature death. This tendency of increased morbidity and mortality is seen in patients with type $2 \mathrm{DM}$ because of the commonness of this type of DM, its insidious onset and late recognition, especially in resource-poor developing countries like India. ${ }^{2}$

The risk of coronary heart disease (CHD) is 2-3 times higher in diabetics than in non diabetics. CHD is responsible for 30 to 50 percent of deaths in diabetics over the age of 40 years in industrialized countries. In fact, diabetes is listed 
among the five most important determinants of the cardiovascular disease epidemic in $\mathrm{Asia}^{3}$

\section{Materials and Methods}

The present study was conducted in two groups classified as

Group (1)100 normal individuals

Group (2) 100 Diabetics Type-2

The study was carried out in 100 Type- 2 diabetic patients in the age group of 35-75 years with duration of diabetes ranging from 6 months to 20 years. Control Group consists of 100 normal individuals who matched with case in age, sex and socio economic condition as far as possible.

Informed written consent was taken from the subjects prior to the start of the study.

Data Analysis- Student's T-test and Chi-square test were applied. Results were presented as mean \pm SD or no. of patients (percent); $\mathrm{P}$ value $<0.05$ defined statistical significant difference.

\section{Results}

A total sample size of 200 with 100 normal individuals and 100 diabetic patients were included in the study.

Table 1: Socio-demographic variable

\begin{tabular}{|l|c|c|c|}
\hline $\begin{array}{l}\text { Socio-demographic } \\
\text { variable }\end{array}$ & Group-I & Group-II & p-value \\
\hline $\begin{array}{l}\text { Age (Yrs) } \\
\text { Mean } \pm \text { SD }\end{array}$ & $51.4 \pm 7.2$ & $50.9 \pm 8.1$ & $>0.05$ \\
\hline Male : Female & $64: 36$ & $62: 38$ & $>0.05$ \\
\hline Hindu : Muslim & $93: 7$ & $92: 8$ & $>0.05$ \\
\hline
\end{tabular}

Mean age of the group-I was $51.4 \pm 7.2$ years and group-II was $50.9 \pm 8.1$ years. Majority were males \& Hindu in both group as compared to females \& Muslim.

Table 2: Comparison of heart rate of normal persons and diabetic patients

\begin{tabular}{|l|c|c|}
\hline Heart rate & Group-I & Group-II \\
\hline Mean & 82.64 & 84.06 \\
\hline SD & 10.23 & 11.03 \\
\hline p-value & $>0.05$ & \\
\hline
\end{tabular}

The mean value of heart rate in 100 Diabetic patients was found to be 84.06 with standard deviation of 11.03 which higher when compared with the mean value of heart rate in 100 normal people which is 82.64 with standard deviation of
10.23. But this difference was statistically not significant $(p>0.05)$

Table 3: Comparison of Mean arterial pressure of normal persons and diabetic patients

\begin{tabular}{|l|c|c|}
\hline Mean arterial pressure & Group-I & Group-II \\
\hline Mean & 93.98 & 96.84 \\
\hline SD & 7.09 & 7.84 \\
\hline p-value & $>0.05$ & \\
\hline
\end{tabular}

Mean arterial pressure of Diabetic patients was found to be $96.84 \mathrm{mmHg}$ with a standard deviation of 7.84 which again is more than mean arterial pressure of normal persons which is 93.98 $\mathrm{mmHg}$ with standard deviation of 7.09. Though there is a difference in mean arterial pressure among two groups, but it was not statistically significant $(p>0.05)$

\section{Discussion}

The mean value of heart rate in 100 Diabetic patients was found to be 84.06 with standard deviation of 11.03 which higher when compared with the mean value of heart rate in 100 normal people which is 82.64 with standard deviation of 10.23. But this difference was statistically not significant $(\mathrm{p}>0.05)$

Similar results were found in previous studies of Ewing DJ, Martyn CN (1985) ${ }^{4}$, Ziegler D, Zentel $\mathrm{C}$ in $(2006)^{5}$ where it was proved that heart rate of Diabetic are more when compared to normal due to vagal damage or due to decrease vagal tone.

Mean arterial pressure of Diabetic patients was found to be $96.84 \mathrm{mmHg}$ with a standard deviation of 7.84 which again is more than mean arterial pressure of normal persons which is 93.98 $\mathrm{mmHg}$ with standard deviation of 7.09. Though there is a difference in mean arterial pressure among two groups, but it was not statistically significant $(\mathrm{p}>0.05)$

According to previous studies of Grossmann et $\mathrm{al}(1996)^{6}$ in Ann Intern Med (1996) patient with Diabetes and hypertension have a higher incidence of coronary artery disease than do patient with Diabetes or Hypertension alone. In Isfahan Diabetes prevention study ${ }^{7}$ there is increase in systolic \& diastolic pressure and also 
increase in mean arterial pressure in Diabetics and they are also at high risk.

\section{Conclusion}

There is increased need for regular health checkups especially of the cardiovascular system to prevent complications.

\section{References}

1. American Diabetes Association. Diagnosis and classification of diabetes mellitus. Diabetes Care 2012;35(suppl 1):S64e71.

2. Patel P, Macerollo A. Diabetes mellitus: diagnosis and screening. Am Fam Physician 2010;81:863e70.

3. Unger RH, Grundy S. Hyperglycemia as an inducer as well as a consequence of impaired islet cell function and insulin resistance: implications for the management of diabetes. Diabetologia 1985;28:119e21.

4. Ewing DJ, Martyn CN (1985) The value of cardiovascular autonomic function test: 10 yrs experiment in Diabetes. Diabetes Care Vol.8:491-498.

5. Ziegler D., Zental C. (2006). Prevalence of poly neuropathy in pre-diabetics and diabetes associated with abdominal obesity and micro angiopathy. Text Book of Diabetes 2008:31:464-469.

6. Grossman G, Schwentikowski M, Keck FS, Hoher M, Steinbach G, Osterhues H, Hombach V. Signal-averaged electrocardiogram in patients with insulindependent (type 1) diabetes mellitus with and without diabetic neuropathy. Diabetic Med. 2004;14:364-369.

7. Janghorbani, Amini M. Comparison of systolic and diastolic blood pressure with pulse pressure and mean arterial pressure for prediction of type 2 diabetes: the Isfahan Diabetes Prevention Study. Endokrynol Pol. 2011;62(4):324-30. 